\title{
Development of an Identified Spinal Commissural Interneuron Population in an Amniote: Neurons of the Avian Hofmann Nuclei
}

\author{
Anne Lill Eide ${ }^{1}$ and Joel C. Glover ${ }^{2}$ \\ ${ }^{1}$ Department of Physiology, and ${ }^{2}$ Department of Anatomy, Institute of Basic Medical Sciences, University of Os/o, 0317 \\ Oslo, Norway
}

The commissural interneurons of the Hofmann nuclei $(\mathrm{HN})$ of the avian spinal cord (The axonal projections of the Hofmann nuclei in the spinal cord of the late stage chicken embryo, Anat Embryol (Berl), A. L. Eide, 1996, Vol 193, pp 543-557) provide a unique opportunity to describe the development of an identified spinal commissural axon projection and its terminal collaterals in an amniote vertebrate. Here, we use the lipophilic tracer Dil to label these and other commissural projections anterogradely and retrogradely from the time the HN neurons are born. $\left[{ }^{3} \mathrm{H}\right]$ thymidine birthdating shows that the final mitoses of $\mathrm{HN}$ neurons occur at stages 21-24 [developmental day (d) 4]. By direct comparison, this follows the generation of motoneurons and of large, dorsally located commissural interneurons. The first HN neurons reach the ventrolateral margin of the spinal cord by $d 6$ by a radial migration through the ventral horn. Radial migration occurs after the extension of $\mathrm{HN}$ axons across the midline. Thus, HN neurons are determined to be commissural interneurons before attaining their definitive locations. The HN neurons subsequently aggregate into segmentally iterated clusters at the ventrolateral margin of the spinal cord by d8. Also by d8 their longitudinal axons attain mature extent in the ventral funiculus of the contralateral side and begin to sprout collaterals. The collaterals are directed predominantly toward the medial aspect of the ventral horn at all stages, forming by d12 a dense thicket of terminals that thins out over several segments to each side of the HN of origin. The initial direction of collateral outgrowth is largely appropriate for the mature termination pattern of the HN. Terminal arbors, however, are less focused at early developmental stages than at later stages.

Key words: birthdating; spinal interneuron; neuronal migration; axon outgrowth; collateral sprouting; spinal cord; chicken embryo
Spinal interneurons are responsible in large part for the integrated function of the spinal cord. Many project intersegmentally to link different axial levels of the cord, and many of these decussate to effect bilateral coordination. These interneuronal connections engender many complex motor patterns with a spinal autonomy (Fukson et al., 1980; Grillner, 1981; Berkenblit et al., 1989; Stein, 1989; Bizzi et al., 1991; Mussa-Ivaldi et al., 1994) that was appreciated early in the history of neurophysiology and even led to the concept of a spinal "soul" (Pflüger, 1853).

Despite the cardinal role of spinal interneurons in organizing spinal function, relatively little is known about their connectivity, especially in amniotes. This necessarily hampers the study of the development of spinal interneurons, a subject that has received increasing attention in recent years. Existing descriptions of the development of spinal interneurons in amniotes are fragmentary, based mostly on retrograde axonal tracing or immunohistochemistry for cytoskeletal or membrane proteins (for review, see Yaginuma et al., 1994). Such techniques do not facilitate the selective study of specific identified interneuron populations, and they have not provided any information about the development of termination patterns. More complete and selective descriptions are available for the primary spinal interneurons of certain anamniotes (Dale et al., 1987; Roberts et al., 1987, 1988; Kuwada et al., 1990a,b). Although some aspects of spinal interneuronal develop-

Received March 21, 1996; revised June 27, 1996; accepted July 2, 1996.

This work was supported by grants from the Norwegian Medical Research Council and the Nansen Foundation.

Correspondence should be addressed to Anne Lill Eide, Department of Physiology, Institute of Basic Medical Sciences, P.B. 1103 Blindern, University of Oslo, 0317 Oslo, Norway.

Copyright (C) 1996 Society for Neuroscience $0270-6474 / 96 / 165749-13 \$ 05.00 / 0$ ment in anamniotes can probably be generalized to amniotes (Colamarino and Tessier-Lavigne, 1995), a comprehensive description of the development of a specific spinal interneuron type in an amniote embryo would provide an important standard for future studies of spinal cord development.

We have recently shown that the paragriseal Hofmann nuclei $(\mathrm{HN})$ of the avian spinal cord contain commissural interneurons whose spatial isolation makes them especially amenable to anatomical and physiological analysis (Eide, 1996). Paragriseal neurons are found in the spinal cords of all vertebrates, but their anatomy and function have remained obscure (for review, see Eide, 1996). The HN comprise a specific subpopulation of paragriseal neurons that are organized into segmentally iterated aggregations located along the ventrolateral edge of the spinal white matter, between the outlets of the ventral roots. Eide (1996) has shown that the commissural projections from $\mathrm{HN}$ neurons extend over several segments and provide terminal collaterals to a ventromedial region of the gray matter corresponding roughly to lamina VIII. Potential targets of the HN neurons thus include lamina VIII commissural interneurons that are presynaptic to motoneurons (Harrison et al., 1986; Jankowska and Noga, 1990) and the medial dendrites of motoneurons. Afferent input to the HN neurons was shown to derive from a separate population of commissural interneurons lying just lateral to the central canal at lumbar levels (Eide, 1996). These features implicate the HN neurons as integral components of a spinal interneuronal network.

Here we examine the development of the HN neurons in the chicken embryo with particular reference to their birth, migration, axonal projections, and termination patterns. 


\section{MATERIALS AND METHODS}

White Italian chicken embryos were incubated in a forced-draft incubator at $37^{\circ} \mathrm{C}$ until the desired stage, at which time they were either used for neuronal birthdating or killed for axonal tracing. Staging was according to Hamburger and Hamilton (1951). In this paper, we refer both to developmental stage and to day of development (d), which designates an integral multiple of $24 \mathrm{hr}$ of development from the start of incubation.

The $\mathrm{HN}$ are located between two consecutive ventral roots. Their segmental location is designated with reference to the roots. For example, HN-LS5/6 refers to the HN located between the roots of lumbosacral segments (LS) 5 and 6.

Birthdating by autoradiography. Thirty-two embryos at successive stages of development from stage 15 to stage $30(\mathrm{~d} 2-\mathrm{d} 6)$ were exposed by opening a window in the egg. Methyl- $\left[{ }^{3} \mathrm{H}\right]$ thymidine $(20-45 \mu \mathrm{Ci}$; Amersham-TRK686, specific activity $83 \mathrm{Ci} / \mathrm{mmol}$ ) in a volume of $40-90$ $\mu l$ of saline was applied to each embryo through the window with a microliter syringe.

At $\mathrm{d} 14-\mathrm{d} 16$, by which time the $\mathrm{HN}$ are easily identified, the embryos were removed from the egg, anesthetized by cooling in oxygenated PBS, $\mathrm{pH} 7.4$, and killed by decapitation. The preparations were fixed overnight in $4 \%$ formaldehyde in $0.1 \mathrm{M}$ phosphate buffer. A hemisection of the cord including HN-LS5/6 was cut out for further analysis. The tissue was equilibrated in $15 \%$ sucrose in phosphate buffer, mounted in Tissue-Tek O.C.T. compound (Chemi-Teknik, Oslo, Norway), frozen at $-20^{\circ}$, sectioned transversely at $10 \mu \mathrm{m}$ on a cryostat, and mounted onto gelatincoated glass slides. The sections were treated with $1 \mathrm{~m}$ ethanolamine for 10 min to eliminate free aldehyde groups that can react with film emulsion and increase background. They were then dehydrated and rehydrated through a series of ethanol $\left(50 \%-70 \%-96 \%-96 \%-70 \%-\mathrm{H}_{2} \mathrm{O}\right)$ and air dried. Kodak NTB2 emulsion (diluted 1:1 in distilled water) was applied by the method of Kopriwa and LeBlond (1962). The emulsion was exposed for $20 \mathrm{~d}$ at $4^{\circ} \mathrm{C}$, developed in Kodak D19, and counterstained with thionin.

This application method has been shown to give cumulative labeling, as the $\left[{ }^{3} \mathrm{H}\right]$ thymidine evidently remains available throughout the duration of neurogenesis, although this is dependent on the stage of application (Langman and Haden, 1970; Hollyday and Hamburger, 1977; McConnell and Sechrist, 1980). In embryos younger than $48 \mathrm{hr}$ of development, thymidine is apparently metabolized within a few hours such that single or closely spaced multiple applications elicit pulse-labeling during one mitotic cycle (Martin and Langman, 1965). In our experiments, the long-term availability of the applied thymidine was confirmed by the persistent labeling of cells in the ventricular zone and the labeling of nearly all cells using the earliest applications (Hollyday and Hamburger, 1977).

The assessment of birthdate using cumulative labeling is based on the presumption that any neuron that is not labeled has been born before the application of $\left[{ }^{3} \mathrm{H}\right]$ thymidine. The generation of a neuron population is thus chronicled by determining the stage(s) at which labeling ceases.

The sections were examined in the light microscope. Only cells that contained a distinct nucleus in the plane of section were scored. Labeled cells contained grains of developed photoemulsion over the nucleus and were easy to identify. In each preparation, the proportion of labeled to unlabeled HN neurons was established. Motoneurons and large interneurons in the dorsal horn were also scored to correlate the birthdates of the different populations.

DiI tracing. A total of 65 embryos at successive developmental stages from $\mathrm{d} 3$ to $\mathrm{d} 14$ were killed for axonal tracing experiments (Table 1). The spinal cord from thoracic segment (Th) 4 to LS14 was dissected out in cold oxygenated PBS, the ventral and dorsal cartilage (or bone at late stages) was removed, and the dura was slit open. The preparations were fixed in cold $4 \%$ formaldehyde in phosphate buffer and kept refrigerated in this solution for $1 \mathrm{~d}$ to several months before tracer was applied. Variation in time of storage before tracer application did not influence the results.

The lipophilic tracer 1,1'-dioctadecyl-3,3,3',3'-tetramethylindocarbocyanine perchlorate (DiI; Molecular Probes, Eugene, OR) was used as a tracer substance. DiI partitions into the lipid bilayer of cellular membranes and diffuses passively along axons (Honig and Hume, 1986), also in fixed tissue (Godement et al., 1987). Fixed preparations were rinsed with phosphate buffer, drained, and daubed dry with tissue paper. DiI was then applied either in the form of dry crystals on the tip of a needle or with a micropipette as a saturated solution in $100 \%$ ethanol. The preparations were left in fixative at $37^{\circ} \mathrm{C}$ for diffusion to take place. The diffusion time was chosen
Table 1. Number of preparations used for DiI-labeling experiments at each development stage

\begin{tabular}{cr} 
Day of development & Number \\
\hline d3 & 1 \\
d4 & 5 \\
d5 & 10 \\
d6 & 6 \\
d7 & 13 \\
d8 & 7 \\
d9 & 2 \\
d10 & 7 \\
d11 & 1 \\
d12 & 1 \\
d13 & 6 \\
d14 & 0 \\
Total & 7 \\
\end{tabular}

according to developmental stage and type of preparation and varied from 4 hr to $150 \mathrm{~d}$.

Because DiI diffuses throughout the neuronal membrane, both anterograde and retrograde labeling inevitably occur in all neurons that intersect the application site. For anterograde labeling of the HN neurons, DiI was generally applied to HN-LS5/6 or, before the overt appearance of the HN, to the spinal cord at the same level. For retrograde labeling of the HN neurons, DiI was applied unilaterally to the spinal cord either in the middle lumbosacral region or rostral to the lumbosacral region. The various application paradigms and representative examples of anterograde labeling are illustrated in Figure 1.

Labeled preparations were first examined in whole mount. They were then rinsed in phosphate buffer overnight, embedded in $17 \%$ gelatin in phosphate buffer, and sectioned transversely at $50-100 \mu \mathrm{m}$ on a Vibratome (Campden Instruments LTD, $752 \mathrm{M}$ Vibroslice). To maintain the integrity of the labeling, it was necessary to keep the sections wet at all times; even a few minutes of drying disrupted the stain. To attach the wet sections to a glass slide for microscopic examination, the gelatin edges of the sections were melted onto the slide with a hot needle. The sections were covered with $4 \%$ formaldehyde, coverslipped, and could then be stored in slide jars containing $1-2 \%$ formaldehyde at $4^{\circ} \mathrm{C}$ for many months. Contamination of the surface of the section occurred over time, presumably because labeled and unlabeled membranes are disrupted and come into contact there. Thus, microscopic examination of the sections was performed during the first $1-3 \mathrm{~d}$ after sectioning.

Fluorescence microscopy. Whole-mount preparations and transverse sections were examined under a Leitz Ortholux II epifluorescence microscope outfitted with a rhodamine filter.

\section{RESULTS}

This study covers a developmental period characterized by tremendous growth and morphometric change in the spinal cord. Figure 2 provides an anatomical framework for the comparison of results obtained at different stages. The HN can be discerned as protrusions along the lateral edge of the lumbar spinal cord from d8. This is the earliest time at which the HN neurons can be anterogradely labeled selectively.

\section{Birthdating}

The mitoses that generate the $\mathrm{HN}$ neurons occur between stages 21 and 24 . In embryos exposed to $\left[{ }^{3} \mathrm{H}\right]$ thymidine before stage 21 , all $\mathrm{HN}$ neurons were labeled, whereas in those exposed after stage 24 (d4), none was labeled. Two preparations at stage 23 contained, respectively, 80 and $50 \%$ labeled HN neurons.

Two other neuron types could be identified readily in transverse sections and compared with the HN neurons with respect to time of generation: namely, the motoneurons of the lateral motor column and large commissural interneurons located between lam- 

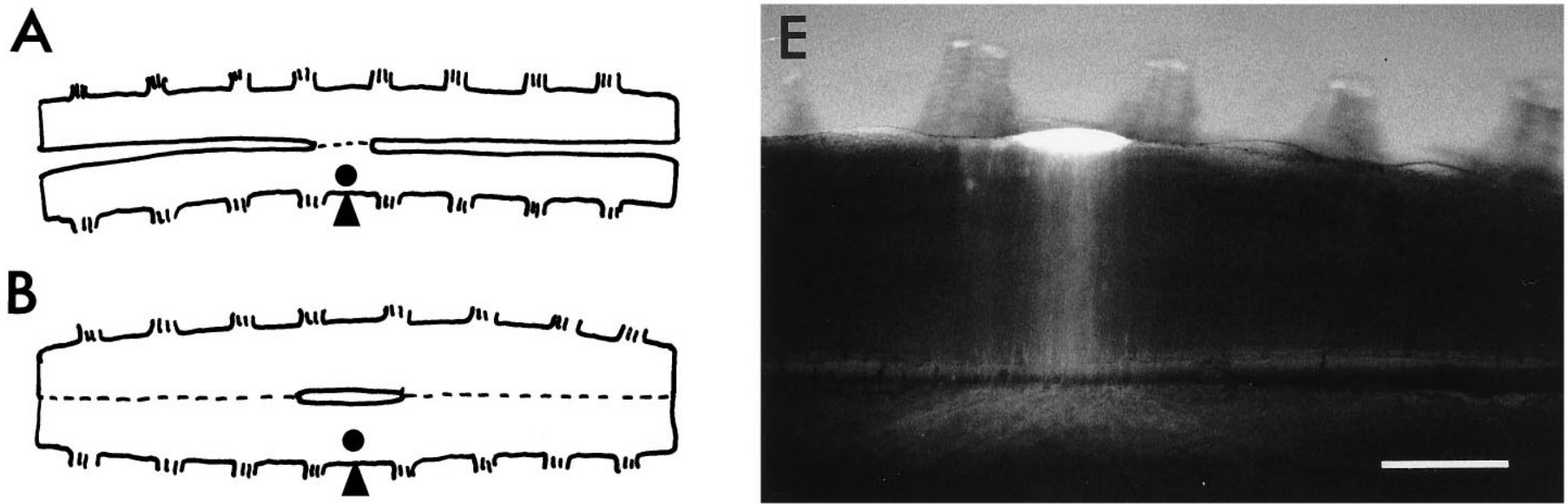

B
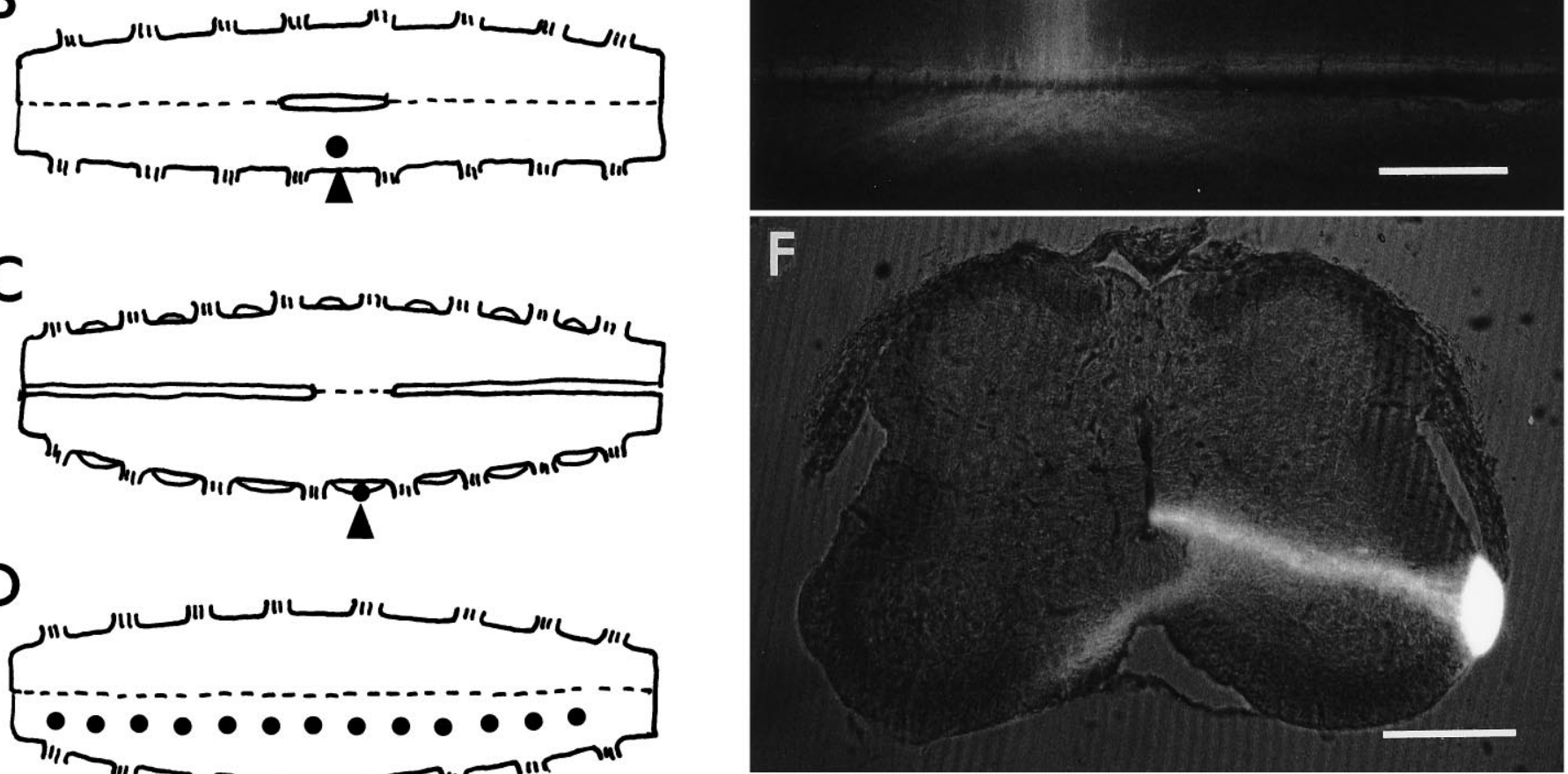

Figure 1. The different DiI application paradigms. $A-D$ illustrate schematically the sites of DiI application (indicated by arrowheads and/or dots). $E$ and $F$ show representative examples of anterograde labeling from a single $\mathrm{HN}$ at $\mathrm{d} 8$. $A$, Anterograde tracing of the entire commissural projection from the level corresponding to a single $\mathrm{HN}$ in preparations from $\mathrm{d} 4$ to $\mathrm{d} 8$. DiI is applied to one side of the spinal cord between two ventral roots. The spinal cord is split along the midline except for between the two roots. This restricts the anterograde labeling to those axons crossing within this region. It also eliminates retrograde labeling of commissural interneurons on the contralateral side at all other levels. $B$, Retrograde tracing of commissural interneurons in preparations from d4 to d14. DiI is applied to the ventral and ventrolateral funiculi on one side midway between two ventral roots. The spinal cord is split along the midline at the same level. This eliminates anterograde labeling of commissural axons originating from the injected side. It also restricts retrograde labeling to commissural axons originating from the contralateral side of more rostral and caudal levels. This reveals the distribution of the commissural interneurons, including HN neurons, on the contralateral side, the longitudinal axons of which traverse the injected level. $C$, Selective anterograde tracing of the HN projection. DiI is applied selectively to one HN. The spinal cord is split along the midline except for the region in which the axons from the injected $\mathrm{HN}$ cross. This eliminates retrograde labeling of contralateral commissural interneurons rostral and caudal to the split and allows the $\mathrm{HN}$ axons and collaterals to be viewed in isolation. $D$, Retrograde tracing of the entire HN population. DiI is applied to one side of the spinal cord over many segments. This reveals the longitudinal disposition of the HN somata during the formation of the HN. $E$, Ventral view of a whole-mount spinal cord at d8 in which DiI has been applied to a single HN. The HN axons are visible along their commissural and longitudinal trajectories. $F$, Transverse section through a similar preparation showing the HN axon trajectory directed radially toward the ventral pole of the central canal and then crossing in the ventral commissure. Note that labeling extends all the way to the ventricular surface. This represents the ventricular attachments of radial glia that extend to the HN, not ventricular attachments of the HN neurons themselves (see text). Scale bars: $500 \mu \mathrm{m}$ in $E$ and $200 \mu \mathrm{m}$ in $F$.

inae II and III and at the boundary between the intermediate zone and the dorsal horn (Fig. 3) (Eide and Glover, 1996). At the stages when $\mathrm{HN}$ neurons were labeled with $\left[{ }^{3} \mathrm{H}\right]$ thymidine, the vast majority of each of these other neuron types was unlabeled, indicating that they are born before the HN neurons (Fig. 3). The birthdates we obtained here for the motoneurons are in accord with the observations of Hollyday and Hamburger (1977).

\section{$\mathrm{HN}$ neuron migration and aggregation}

When DiI was injected into the ventral funiculus on one side of the lumbar spinal cord, interneurons projecting ipsilaterally were labeled retrogradely on the same side, and commissural interneurons were labeled retrogradely on the opposite side. The pattern of commissural interneuron labeling changed over time and will be discussed in more detail below. Here we draw attention to a feature of the labeling that bears specifically on the migration of the $\mathrm{HN}$ neurons.

In the immediate vicinity of a unilateral DiI injection, all cells, including neurons and radial glia, were labeled simply because of nonspecific spread. But at levels rostral or caudal to the injected region on the same side, or at any level on the contralateral side, only interneurons whose axons projected to or through the injected region became labeled. This is shown in Figure $4 A$, in a section taken caudal to the injected region on $\mathrm{d} 7$. The labeling of commissural interneurons has been limited to those crossing 

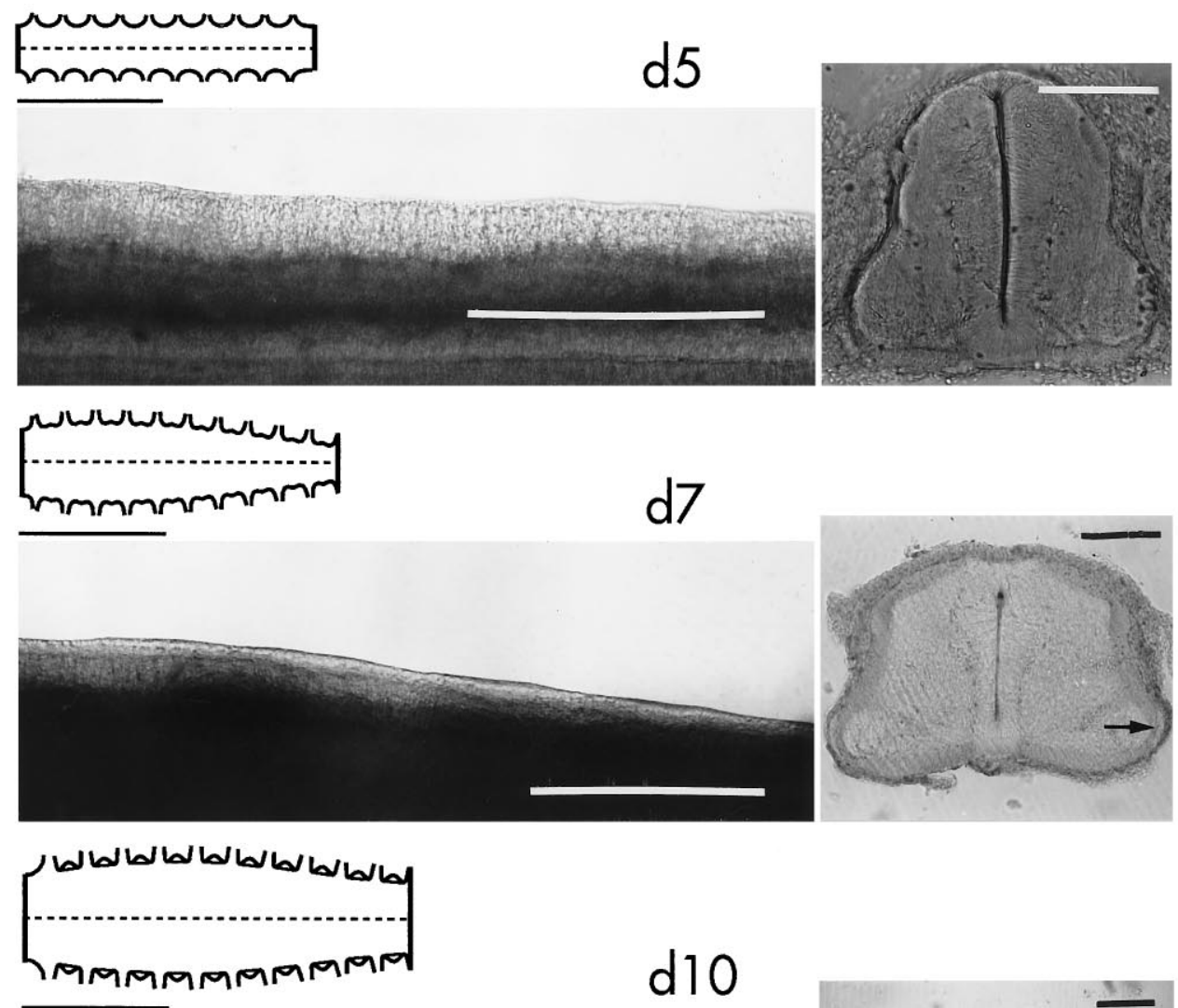

Figure 2. The development of the $\mathrm{HN}$ in the context of the morphometric changes occurring in the spinal cord during the developmental period studied. For each developmental stage, we show: (1) a drawing of a ventral view of the lumbar region of the spinal cord (the series of drawings is at the same scale to illustrate relative size); (2) a photomicrograph of a ventral view of one side of the spinal cord showing the disposition of the HN (first distinctly visible from d8); and (3) a photomicrograph of a transverse section through the lumbar spinal cord at the level of an HN (arrows). Scale bars: $2 \mathrm{~mm}$ in all drawings, $500 \mu \mathrm{m}$ in the left photomicrographs, and $200 \mu \mathrm{m}$ in the right photomicrographs.
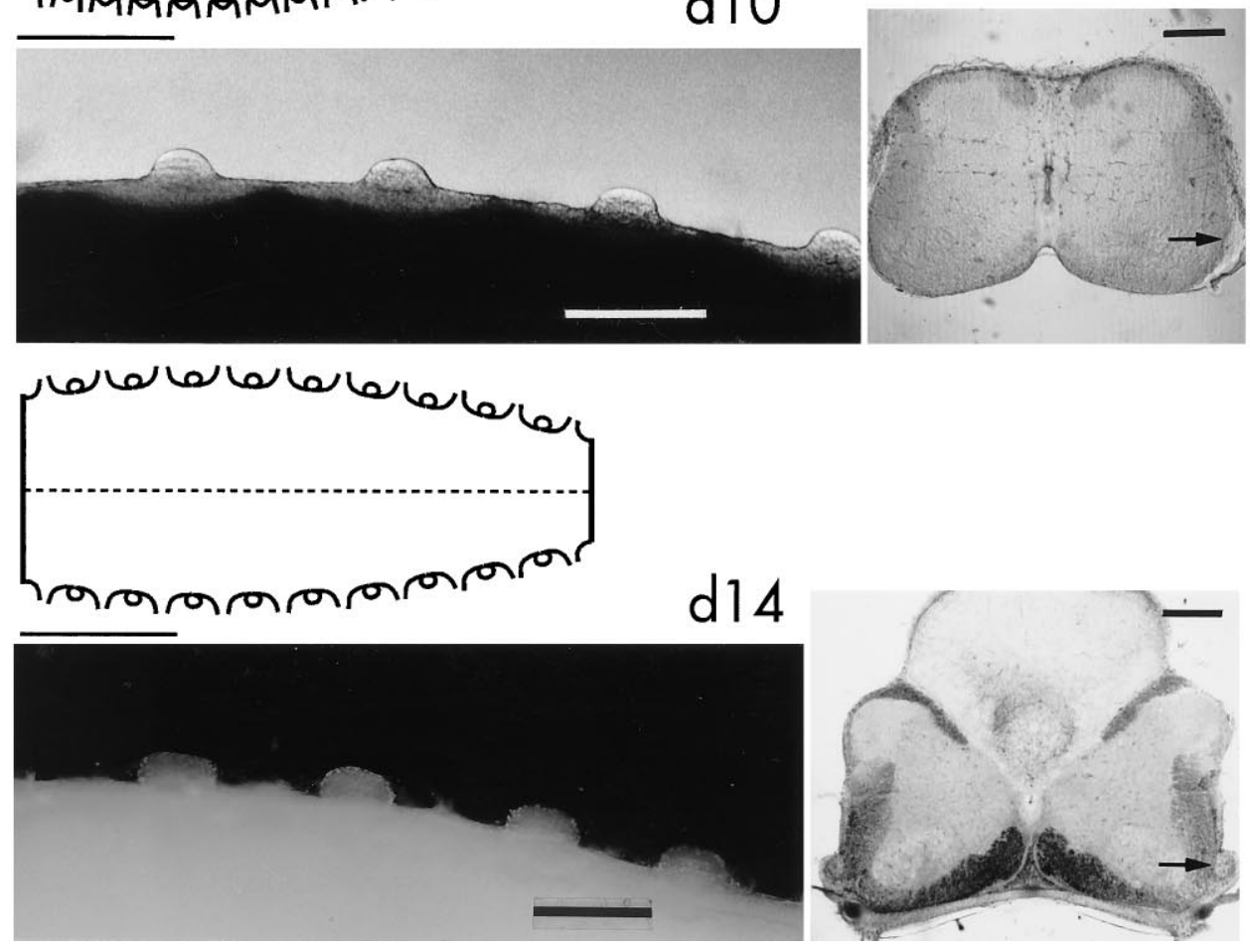

rostral and caudal to the injected region by the midline split, as shown in Figure $4 D$. The domains of the lateral motor columns are outlined by labeled interneurons and their dendrites (both sides), as well as by labeled ventral axon tracts (injected side). The labeled processes radiating through the lateral motor column toward the lateral margin of the spinal cord on the side contralateral to the injection are the retrogradely labeled axons of the HN neurons, which were consistently seen only on the contralateral side (Fig. 4A). Elongated somata with radial orientation and devoid of dendrites were clearly associated with these axons on d6 (Fig. 4B,C), but no longer by d8. Our interpretation is that the $\mathrm{HN}$ somata have already extended a commissural axon by this stage of their development, but are still in the process of migrating laterally by nuclear translocation. The temporal sequence of events thus appears to be as follows: HN neurons, after undergoing their terminal mitoses in the ventral ventricular zone by $\mathrm{d} 4$, extend 

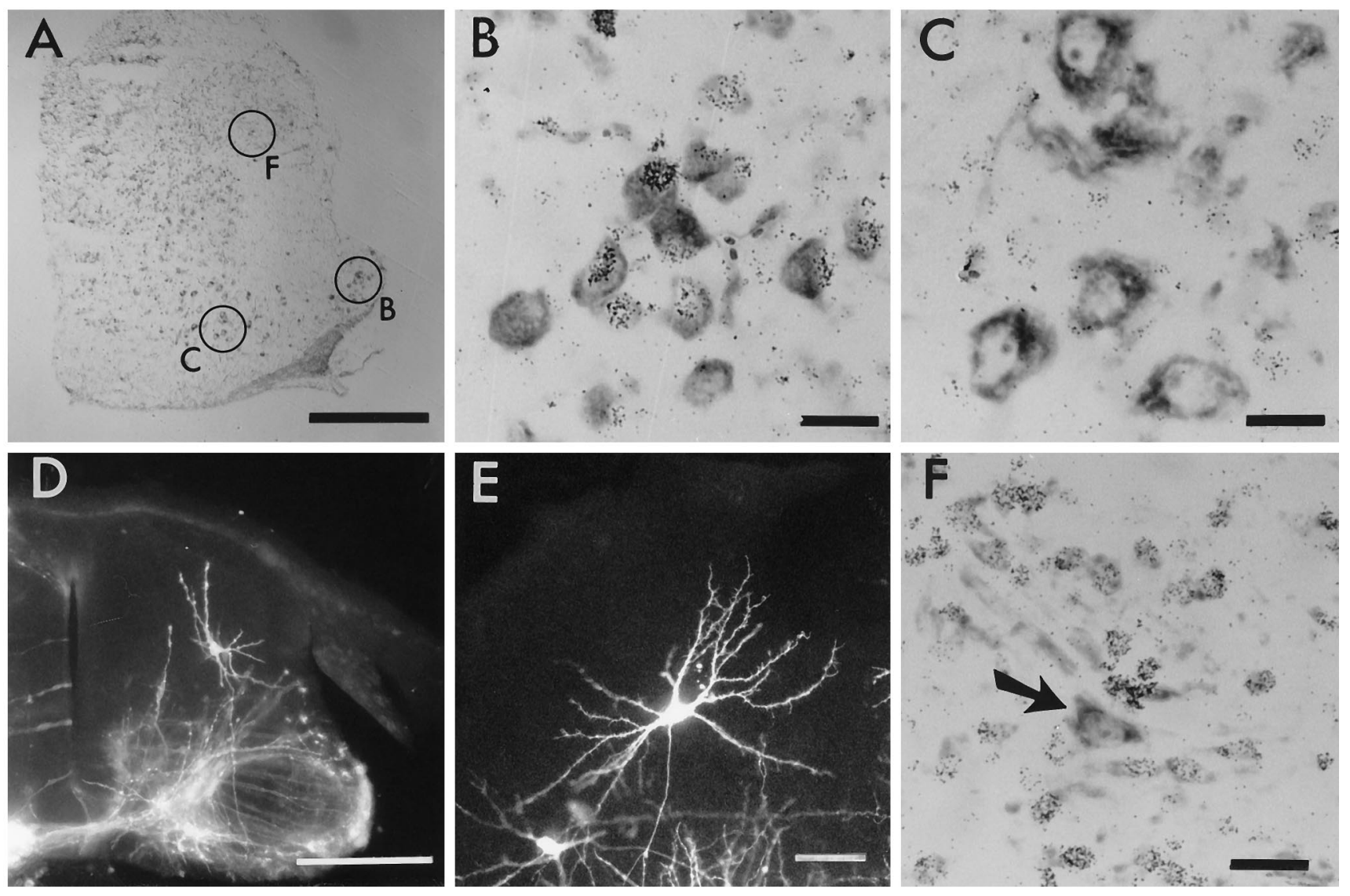

Figure 3. $\left[{ }^{3} \mathrm{H}\right]$ thymidine birthdating of $\mathrm{HN}$ neurons and other neuron populations. $A$, Autoradiographic transverse section from the spinal cord of a d15 embryo labeled with $\left[{ }^{3} \mathrm{H}\right]$ thymidine at stage 23 (early d4). Circles enclose the regions shown in $B$, $C$, and $F$. $B$, Intermingled labeled and unlabeled $\mathrm{HN}$ neurons; the latter were born before $\left[{ }^{3} \mathrm{H}\right]$ thymidine application. $C$, All motoneurons in the lateral motor column are unlabeled, demonstrating that this neuron population is born before the $\mathrm{HN}$ cells. $D$, Retrograde labeling of a large dorsal commissural interneuron at d7. $E$, Retrograde labeling of a large dorsal commissural interneuron at d15. F, Large dorsal interneurons of the same size, shape, and location as in $E$ are unlabeled (arrow), demonstrating that this neuron population is born before the $\mathrm{HN}$ neurons. Scale bars: $500 \mu \mathrm{m}$ in $A, 50 \mu \mathrm{m}$ in $B, C, E$, and $F$, and $200 \mu \mathrm{m}$ in $D$.

migratory leading processes through the lateral motor column to the pial surface, parallel to radial glia, and begin to migrate by nuclear translocation. By d6, while still migrating radially, they have extended commissural axons across the midline. By d8, their radial migration brings them to their definitive locations at the ventrolateral margin of the spinal cord.

In addition to the radially oriented leading processes of the $\mathrm{HN}$ neurons, radial glia (which are not labeled in Fig. 4) extend through the lateral motor column. At d8, selective application of DiI to the HN typically labeled not only the HN commissural axons but also fibers that extended to the ventricular surface (Fig. $1 F)$. These ventricular attachments were not labeled when the $\mathrm{HN}$ axons were traced retrogradely from the contralateral side. Thus, they cannot be ventricular attachments of the HN neurons themselves. Rather, they must be the ventricular attachments of radial glia cells that extend from the ventricular surface to the HN. Evidently these cells are eliminated or retract from the ventricular surface after $\mathrm{d} 8$, because application of DiI to the $\mathrm{HN}$ at later stages did not label any ventricular attachments.

After their radial migration, the $\mathrm{HN}$ underwent a longitudinal aggregation. At d7, the $\mathrm{HN}$ neuron population appeared as a fairly continuous column along the ventrolateral margin (Fig. 5). By $\mathrm{d} 8$, the column was clearly segmented into clusters that gradually coalesced to form the definitive protruding HN (Fig. 5). Support for a segmental aggregation of an initially unsegmented column of HN neurons comes from the relationship between soma and axon distributions in late stage embryos, as described by Eide (1996). Although the HN neuron somata are clearly segmentally clustered, their commissural axons are evenly distributed along the length of the spinal cord. The most likely explanation is that radial migration of HN somata and commissural axon extension occurs evenly along the entire length of the lumbar cord, leaving a record of the initial unsegmented distribution as the $\mathrm{HN}$ neurons aggregate into segmental clusters.

\section{The commissural interneuron population as a whole}

The first commissural axons in the lumbar spinal cord of the chicken embryo cross the midline at about $\mathrm{d} 3$, and then turn either rostrally or caudally in the contralateral ventral funiculus (Yaginuma et al., 1991). At the earliest stage we examined, stage 23 (d4), the first few commissural axons had already crossed the ventral midline (see below). From then on there was a successive recruitment of commissural axons as shown by the increasing number of retrogradely labeled neurons contralateral to the DiI application. This retrograde tracing did not label the $\mathrm{HN}$ neurons selectively, but also labeled other commissural interneurons (Fig. 6). Some of these could be distinguished before the radial migration of the HN neurons through the lateral motor column. The commissural interneurons labeled retrogradely at $\mathrm{d} 5$ were located predominantly dorsal to the lateral motor column. Their axons 

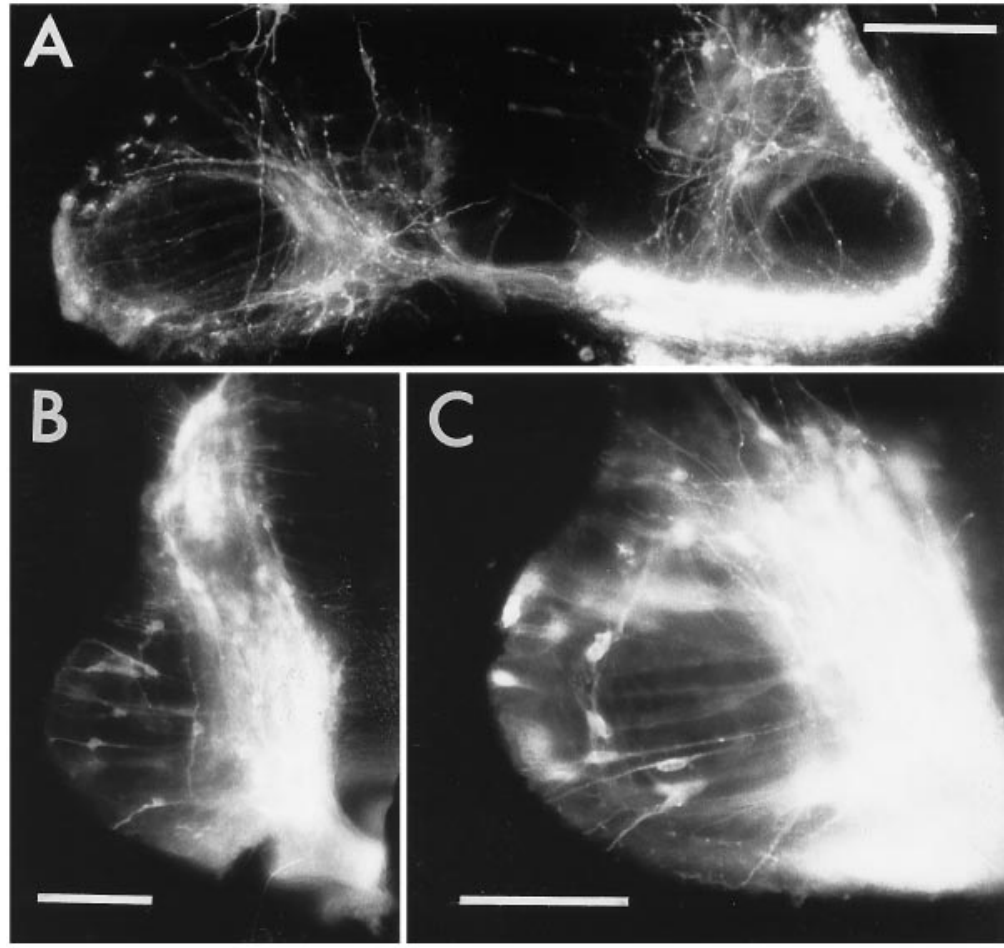
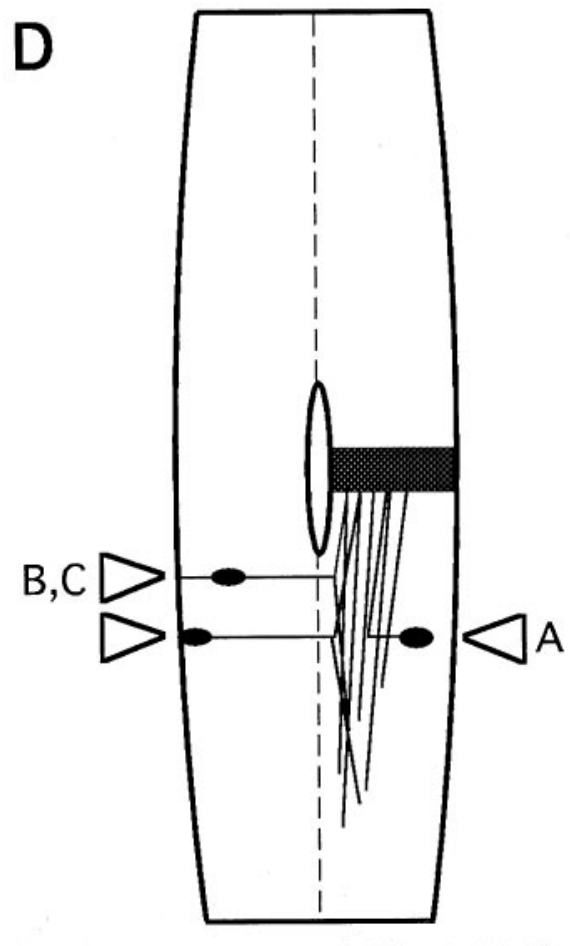

Figure 4. Lateral migration of $\mathrm{HN}$ neurons. Transverse sections through the ventral spinal cord showing the distribution of retrogradely labeled commissural interneurons at $\mathrm{d} 7(A)$ and $\mathrm{d} 6(B, C)$ after DiI application to the right side as shown in $D$. $A$, The labeling pattern is different on the injected (right) and contralateral (left) sides immediately caudal to the level of injection. Radial processes extending through the lateral motor column are present only on the side contralateral to the injection and represent the retrogradely labeled axons of the HN neurons. $B$ and $C$ show examples of somata (presumed HN somata) associated with these axons. $D$ summarizes schematically the distribution of axons and cell bodies labeled by this DiI application procedure. The small black ellipses represent interneurons, HN neurons on the left side and an ipsilaterally projecting interneuron on the right, the latter lying lateral to longitudinal axons. Hatching indicates the DiI application site, and arrowheads indicate the location of the sections shown in $A-C$. Scale bars, $100 \mu \mathrm{m}$.

projected first laterally to the lateral margin, where they extended ventrally, skirting the medial aspect of the nascent lateral motor column before striking across the midline through the most ventral region of the floor plate (Fig. 6). Occasional commissural interneuron somata labeled at $\mathrm{d} 5$ were located in the ventricular zone (Fig. 6). By d6, the number of retrogradely labeled commissural interneurons had increased, and many were located medial to the lateral motor column (Fig. 6). With continued development, the commissural interneuron population increased further in number, with a distribution skewed toward the ventral half of the spinal cord by $\mathrm{d} 8$ (Fig. 6). The number of labeled commissural interneurons fell with distance from the injected segment (Fig. 6). Characteristically large dorsally located commissural interneurons were among those with the longest longitudinal projections.

\section{Development of longitudinal projections}

The extension of longitudinal axons after bifurcation of the commissural axon population was examined using three different experimental approaches. In the first, used from $\mathrm{d} 4$ to $\mathrm{d} 7.5$, we labeled anterogradely all commissural axons crossing at a specific level by applying DiI to the ventral region of one side of the spinal cord (Fig. 7). The ventral commissure was split rostral and caudal to the DiI application site to restrict labeling to the commissural axons crossing at the level of application (Fig. $1 A$ ). In this case, it was impossible to distinguish labeled $\mathrm{HN}$ axons from other labeled axons. In the second, used from d5.5 to d8, we labeled retrogradely all commissural axons that had turned or bifurcated to extend through a given spinal level by applying DiI to the ventral funiculus on one side of the spinal cord (Fig. $1 B$ ). In this case, from $\mathrm{d} 7$ onward, we could determine selectively the longitudinal extent of the $\mathrm{HN}$ axons by virtue of the retrograde labeling of their distinctly localized and easily identified somata (see Fig. 5). In the third, used from d8 on, we selectively labeled the axons of the HN neurons anterogradely by applying DiI to the $\mathrm{HN}$ itself (Fig. 1C). Projection distances were quantitated in at least three preparations from each developmental day, starting at d4 (stage 23) (Fig. 8).

By d4, a few commissural axons extended directly across the ventral midline, some of them then turned either rostrally or caudally or bifurcated near the ventrolateral margin and extended longitudinally up to a distance of about one segment in one or both directions (Figs. 7, 8). By d5, the number of commissural axons had increased dramatically and had spurted 4 to 7 segments, or $\sim 1.5 \mathrm{~mm}$, in each direction (Figs. 7,8 ). By d6, the axons had extended about another millimeter in each direction, although this was equivalent to only about two additional segments because of the concomitant longitudinal growth of the spinal cord (Figs. 7, 8). Throughout this period, the rostral and caudal projection distances were roughly symmetrical about the segment of origin.

At d7 and later, we could not determine the full longitudinal extent of the entire commissural axon population because the DiI labeling faded out before reaching the axon termini. This means that some commissural axons must extend many segments in each direction already at an early stage of spinal cord development. By contrast, we could determine the full reach of the $\mathrm{HN}$ axons at all 

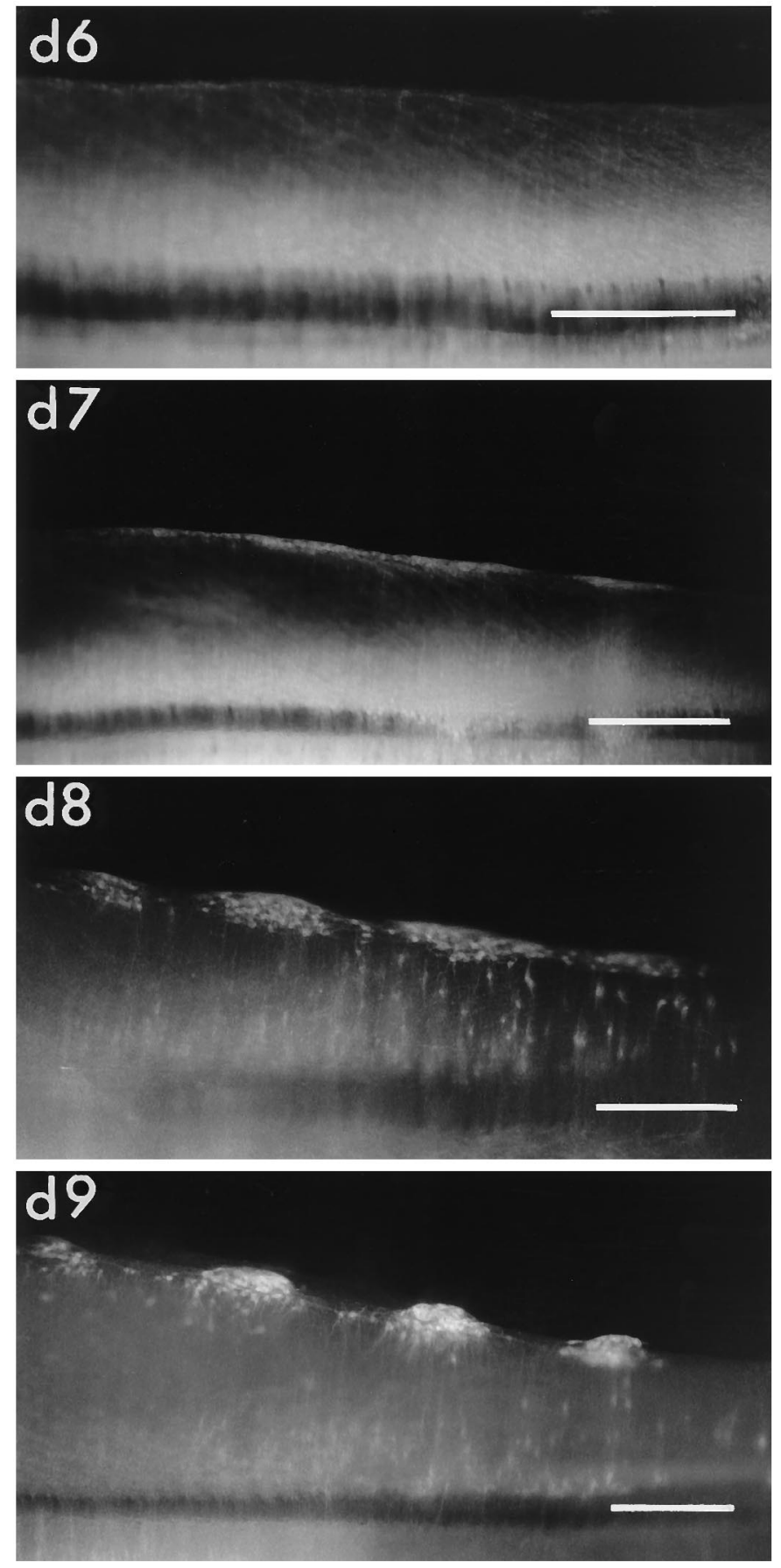

Figure 5. The longitudinal aggregation of HN neurons. Ventral views of the spinal cord at the indicated developmental stages. All HN neurons have been retrogradely labeled as shown in Figure $1 D$. Scale bars, $500 \mu \mathrm{m}$.

stages because these were always strongly labeled throughout their extent.

At $\mathrm{d} 8$, the earliest time at which the $\mathrm{HN}$ axon population could be labeled selectively (Figs. 7, 8), the HN axons had extended about four segments in each direction. This is approximately equivalent to the mature HN projection (Eide, 1996), but was less than the segmental extent attained by the entire commissural axon population by d6. Of course, in terms of absolute distance, the HN axons must continue to elongate by intercalary growth even after d8 to maintain their segmental reach in the face of continued lengthening of the spinal cord (Fig. 8B) (Eide and Glover, 1995).

\section{Development of collateral branches}

When we labeled anterogradely all commissural axons crossing at a given level, the process of collateral sprouting could be followed in transverse sections rostral and caudal to the DiI application (Fig. 9). The first collaterals appeared at d7, i.e., approximately $3 \mathrm{~d}$ after the first commissural axons had begun to extend longitudinally in the ventral funiculus. Initially, the collaterals were straight unbranched neurites oriented at various angles into the gray matter in the transverse plane. Later, the angle made by the collaterals in the transverse plane generally depended on the mediolateral positions of the parent longitudinal axons; collaterals originating from more medial axons projected more dorsad, whereas those originating from more lateral axons projected more mediad (not shown). The collaterals were thus oriented approximately parallel to radial glia. By $\mathrm{d} 9$, the collaterals had initiated secondary branching (not shown).

When we first selectively labeled the $\mathrm{HN}$ axons anterogradely at $\mathrm{d} 8$, only a very few collaterals were present, and these were slightly less mature than the collaterals labeled from the entire commissural projection at $\mathrm{d} 8$. This indicates that the $\mathrm{HN}$ axons lag the earliest commissural axons slightly in the establishment of collaterals. Moreover, it shows that the entire process of $\mathrm{HN}$ collateral sprouting can be followed by selectively labeling the definitive $\mathrm{HN}$, starting at $\mathrm{d} 8$.

The first HN collateral sprouts appeared along much of the longitudinal extent covered by the $\mathrm{HN}$ axons on $\mathrm{d} 8$ (Fig. 10). With further development, collaterals gradually increased in number, most rapidly at proximal positions. Secondary branching was initiated between $\mathrm{d} 10$ and d12 (Fig. 10). The collaterals gradually became more elaborate, and by $\mathrm{d} 14$ the $\mathrm{HN}$ collateral arbors contacted much of the ventromedial gray matter (Fig. 10). Most collaterals were oriented toward the medial region of the ventral horn throughout this process, a feature especially prominent in collaterals arising distally, where the parent longitudinal axons have acquired more lateral positions. The termination pattern at d14 is similar to, but less focused than, the heavy termination in lamina VIII seen at d18 (Eide, 1996).

\section{DISCUSSION}

We have described the development of commissural neurons in the avian spinal cord, with special emphasis on the Hofmann nuclei major located at the ventrolateral margin of the spinal cord. The HN neurons exhibit many of the general properties of commissural spinal interneurons, and thus provide a good model for the study of commissural interneuron development in amniotes (Eide, 1996). Their axons follow the typical commissural interneuron trajectory, crossing the midline at the level of the soma and extending longitudinally in the ventrolateral white matter with a gradual shift to more lateral positions from proximal to distal. They also have specific termination and connectivity patterns that distinguish them from other commissural interneurons. They are generated within a relatively narrow window of developmental time, differentiate nearly synchronously, and eventually become anatomically isolated. These features have facilitated the first selective description of the differentiation of an identified population of spinal commissural interneurons, from birth through the formation of axon projections and terminal arbors. 

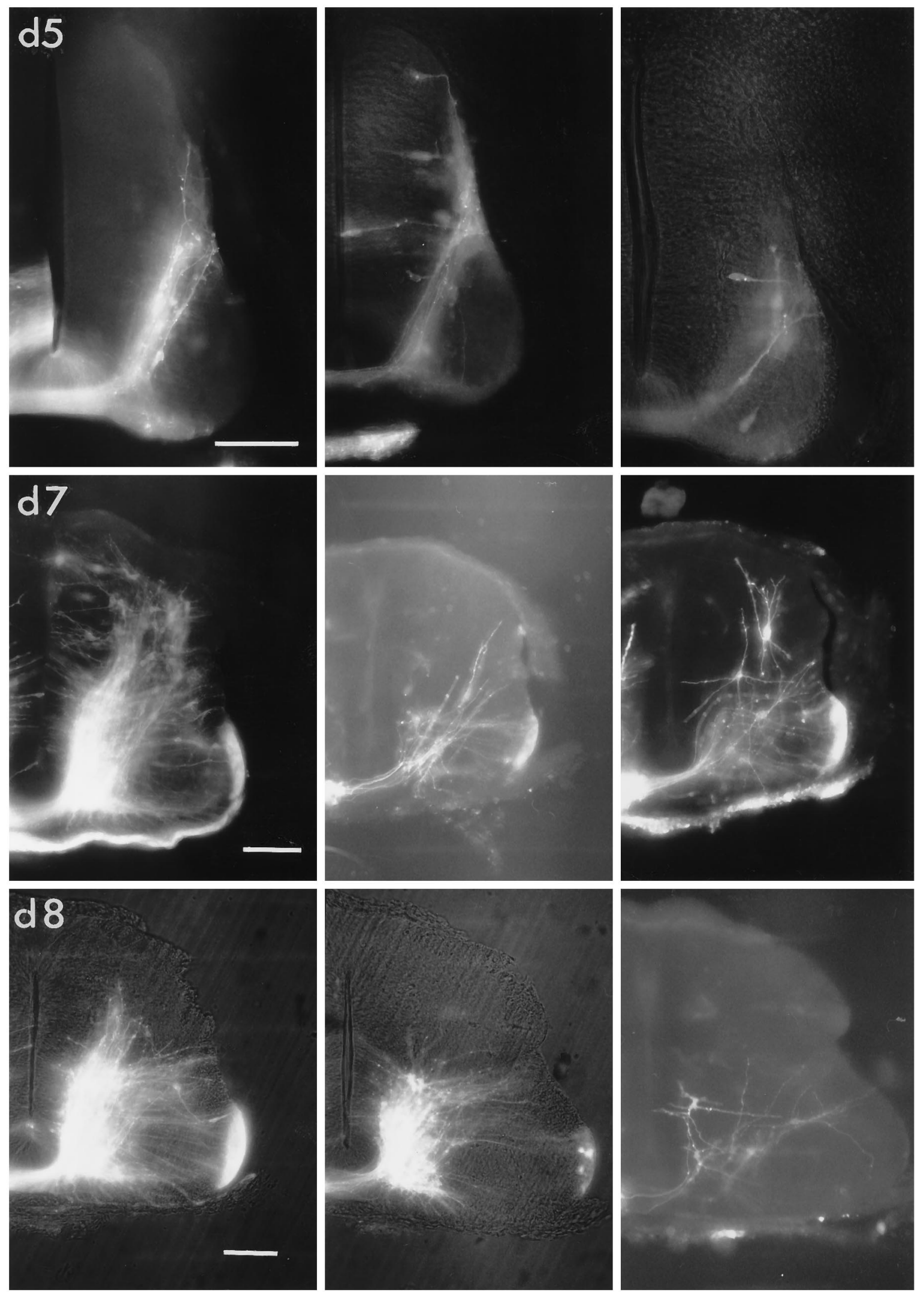

Figure 6. Retrograde labeling of the entire commissural interneuron population located between LS5 and LS6 at the indicated developmental stages (DiI application as in Fig. 1B). Each row of plates shows the pattern of labeling at the same indicated stage, with distance rostrad increasing from left to right over a distance of about two to three segments. Scale bars, $100 \mu \mathrm{m}$. 


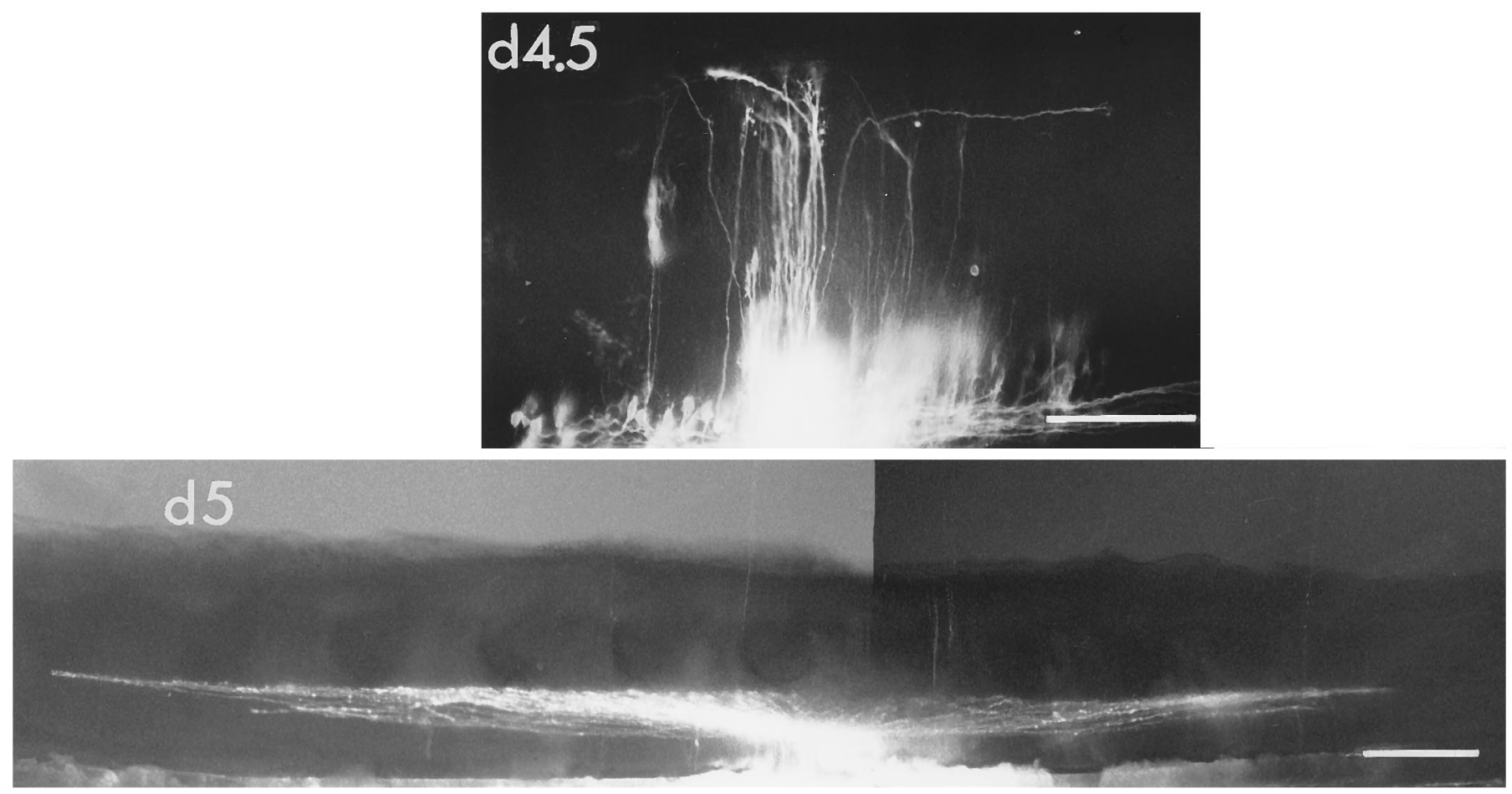

\section{d6}
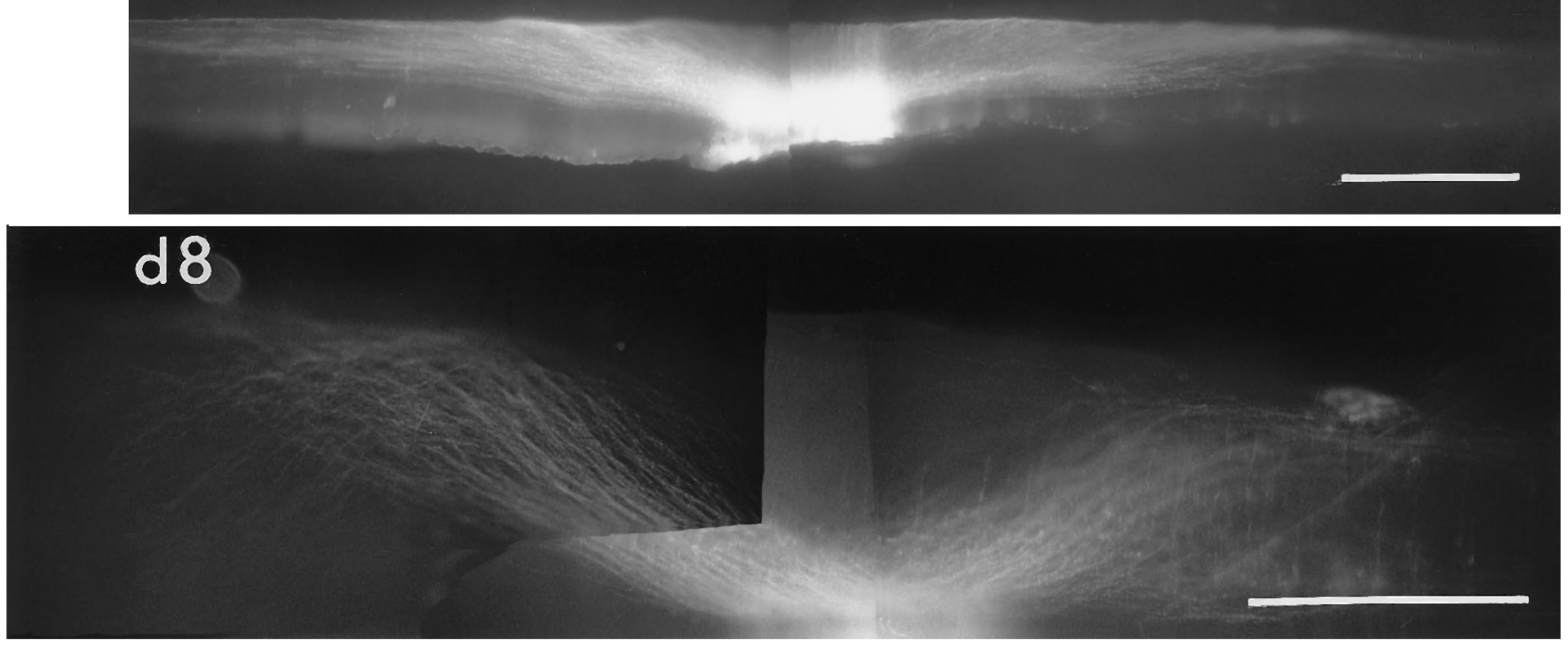

Figure 7. The progressive longitudinal growth of axonal projections from commissural interneurons. Ventral views of the spinal cord at the indicated developmental stages. At d8, a single $\mathrm{HN}$ is labeled selectively; at earlier stages, the entire commissural axon population is labeled. Scale bars: $100 \mu \mathrm{m}$ (d4.5), $500 \mu \mathrm{m}$ (all subsequent stages).

\section{Birth and radial migration}

The HN neurons are born between stages 21 and 24, starting about a half day after the very first interneurons are born in the lumbar spinal cord (Hollyday and Hamburger, 1977; McConnell and Sechrist, 1980). The earliest born interneurons have positions similar to those of the dorsally located commissural interneurons shown in Figure 3, $D$ and $E$. They are likely to correspond to the dorsal-lateral border cells described by Oppenheim et al. (1988) and are likely to be among the dorsally located interneurons that pioneer the commissural pathway in the spinal cord (Yaginuma et al., 1990). Hence, some specific types of spinal interneurons are born and differentiate in the lumbar spinal cord before the first $\mathrm{HN}$ neurons are born. By contrast, some specific types of spinal interneurons, such as sensory interneurons in lamina II, are clearly born after the HN neurons (Eide and Glover, 1996). This suggests that different types of spinal interneurons have specific generation times, much as different laminar populations of neurons in cortex, retina, optic tectum, and other structures have specific generation times (for review, see Jacobson, 1991).

By analogy to the mammalian cortex (McConnell, 1992), the 

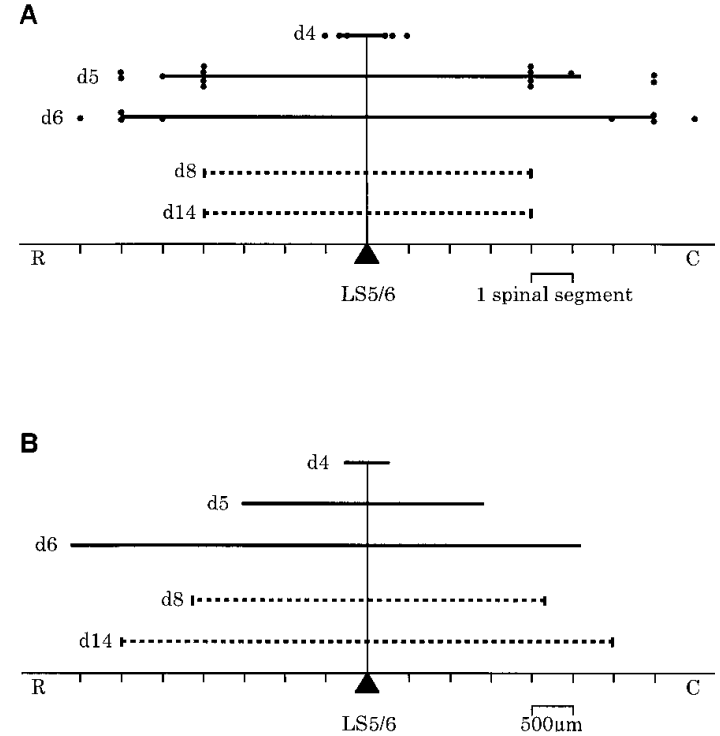

Figure 8. The progressive longitudinal growth of axonal projections from the entire commissural interneuron population located between LS5 and LS6 (points and solid lines) or from HN-LS5/6 (dashed lines). Axon extent is expressed in terms of segmental reach $(A)$ and absolute length $(B)$ at the indicated developmental stages. Points represent maximum extents observed in single preparations, whereas the solid lines represent averages of these. Points are only shown for the early stages when maximum extents are more variable. For the entire commissural axon population, average extents are derived from three, seven, and four preparations at $\mathrm{d} 4$, $\mathrm{d} 5$, and d6, respectively. For the HN commissural axon population, average extents are derived from three preparations at each of $\mathrm{d} 8$ and $\mathrm{d} 14$.

generation of different subtypes of spinal interneurons at different times could be related to the determination of migratory destination. In particular, the radial migration of the HN neurons, through the existing column of motoneurons and to the ventro- lateral surface of the spinal cord, is a feature that distinguishes the HN neurons from other commissural interneurons.

Although we have not witnessed the migration of $\mathrm{HN}$ neurons from their birth sites in the ventricular zone, their radial trajectories in the ventral neural tube suggest that they are born in the ventral part of the ventricular zone (see Fig. 2). A ventral origin of the HN neurons stands in contrast to the apparent dorsal origin of at least some other commissural interneurons (Oppenheim et al., 1988; Leber and Sanes, 1995) (Fig. 6). Our impression from material such as that presented in Figure 6 (middle top) is that commissural interneurons can in fact originate from virtually any dorsoventral level of the ventricular zone. This would seem to rule out progenitor position along this axis as a potential determinant of the commissural interneuron phenotype.

Somatic motoneurons also originate from the ventral ventricular zone and migrate laterally in advance of the HN neurons, establishing the lateral motor column through which the $\mathrm{HN}$ neurons migrate. Evidently, motoneuron and $\mathrm{HN}$ neuron lineages have diverged before the birth of the motoneurons. After labeling motoneuron progenitors with a retroviral lineage tracer at stages 11-18 (d2-d3), Leber et al. (1990) obtained 55 clones that contained both motoneurons and other cell types, but only one of these contained HN neurons. Thus, separate progenitors for motoneurons and $\mathrm{HN}$ neurons must coexist by these stages in the ventral region of the ventricular zone.

\section{Commissural axon outgrowth}

The radially migrating HN neurons can first be labeled retrogradely from the contralateral side starting at approximately d6. Other commissural interneuron types located medial and dorsal to the motoneuron column evidently are the source of the first commissural axons we have observed with anterograde labeling. Oppenheim et al. (1988) describe five categories of intersegmentally projecting spinal interneurons in $\mathrm{d} 2.5-\mathrm{d} 6$ chicken embryos, with different locations in the transverse plane. Each category
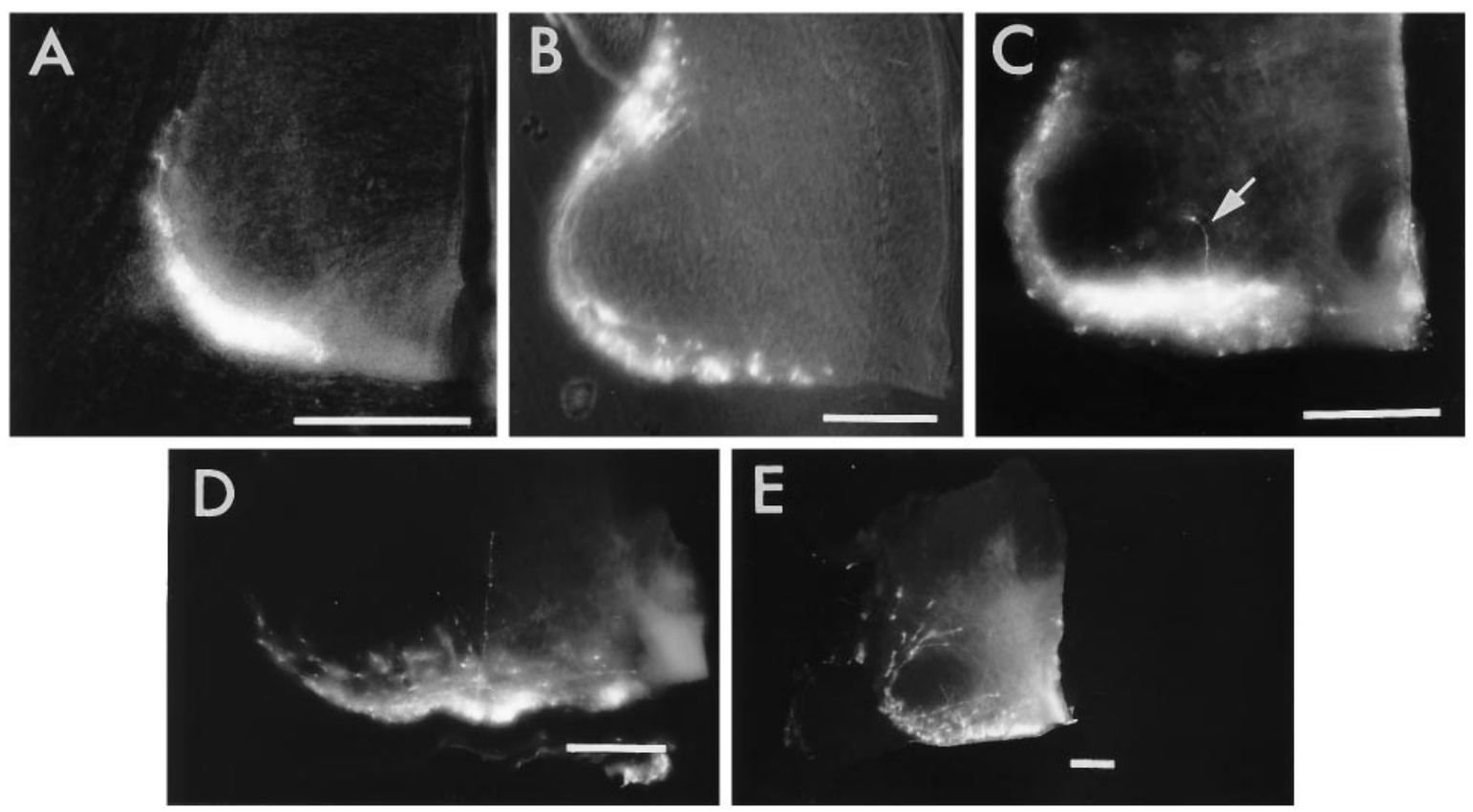

Figure 9. Early development of axon collaterals from the entire commissural interneuron population located between LS5 and LS6. Transverse sections through the contralateral side of the spinal cord. The commissural axon population has bifurcated to extend longitudinally in the ventral and ventrolateral white matter at $\mathrm{d} 5(A)$ and $\mathrm{d} 6(B)$, but collaterals first appear at d7 $(C$, arrow). By d8 $(D, E)$, only a few unbranched collaterals have been elaborated. All sections are from the region just rostral to the DiI application site (DiI applied as in Fig. $1 A$ ). Scale bars, $100 \mu \mathrm{m}$. 

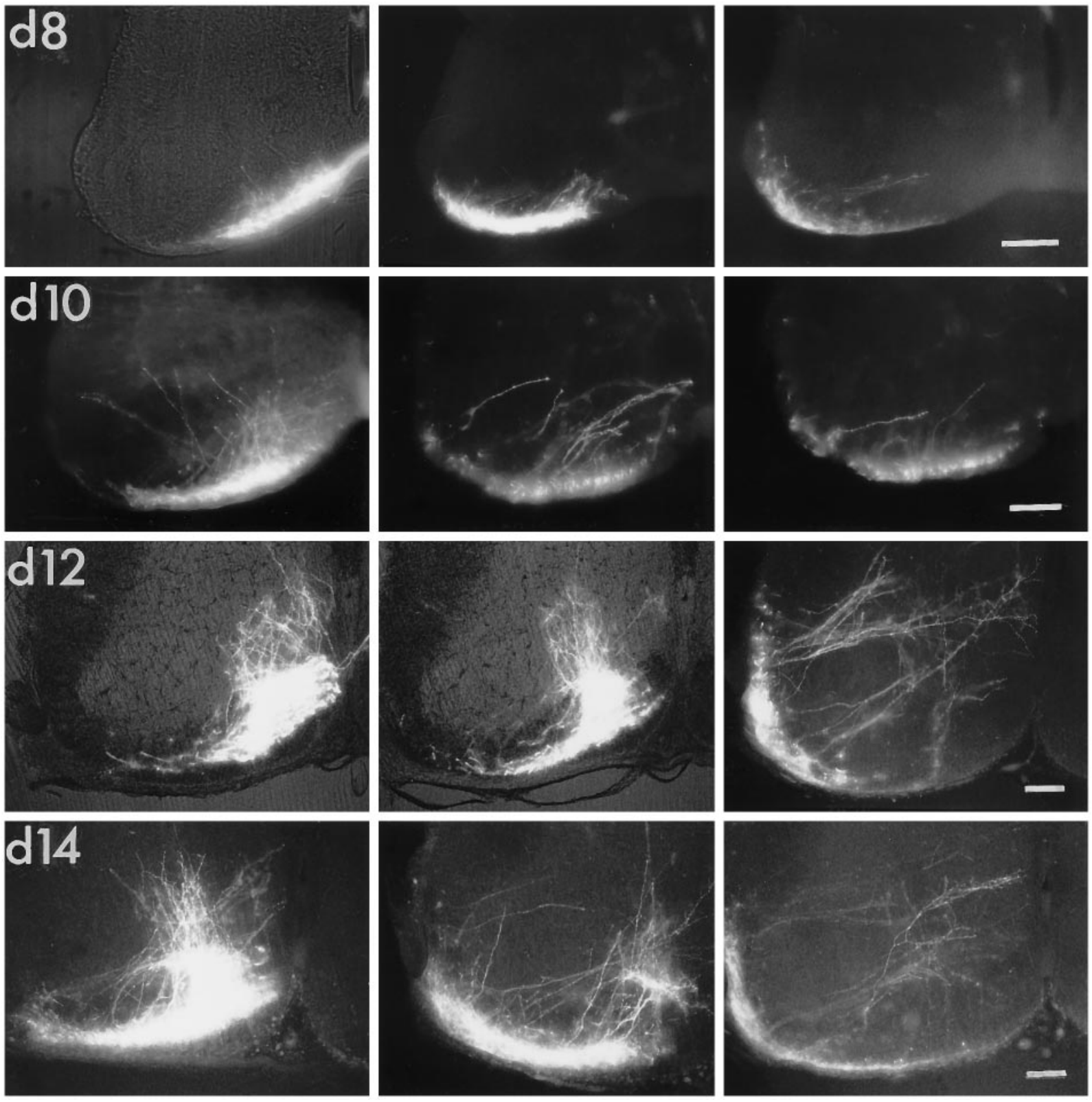

Figure 10. The development of axon collaterals from a single HN-LS5/6 at successively greater distances rostral to the HN (DiI application as in Fig. $1 C)$. Each row of plates shows the pattern of labeling at the same indicated stage, with distance rostrad increasing from left to right over a distance of about four segments. Note the change in the mediolateral location of the longitudinal axons with increasing distance and the corresponding change in angle of collateral ingrowth. Scale bars, $100 \mu \mathrm{m}$.

includes, but is not homogeneously composed of, commissural interneurons. In general, our descriptions of the disposition of commissural interneurons are similar. Not surprisingly, Oppenheim et al. (1988) make no mention of the HN neurons, because these have not yet reached their definitive locations and cannot be selectively identified by d6. But their "ventral-horn" category, located within the ventral horn or along its medial border, might include HN neurons during their radial migration.

The HN neurons can be labeled retrogradely from the contralateral side of the spinal cord before reaching their definitive positions. Thus, they appear to be determined as commissural neurons before or during migration and not by virtue of their eventual location at the ventrolateral margin of the neural tube. In this regard, the $\mathrm{HN}$ neurons are similar to spinal motoneurons.
Before reaching their definitive migratory positions, motoneurons express specific combinations of transcription factors of the LIM homeobox gene family (Tsuchida et al., 1994). The combinatorial expression pattern of these transcription factors predicts the final positions and peripheral axon pathways, and thus functional classes, of the motoneurons (Tsuchida et al., 1994). The implication is that a specific combination of transcription factors triggers the expression of a specific set of the membrane proteins that steer migration and axon pathfinding. Only one LIM transcription factor, Lim-1, is known to be expressed by the HN neurons, but is also expressed by motoneurons and other spinal interneurons and hence does not define the HN neurons as a distinct class (Tsuchida et al., 1994). Because other LIM transcription factors reportedly define distinct subsets of spinal interneurons (Tsuchida 
et al., 1994), it seems plausible that commissural interneurons are differentiated into anatomical and functional subclasses based on transcription factor expression, an issue to which the anatomically isolated $\mathrm{HN}$ neurons provide convenient access.

In general, commissural axon outgrowth in the spinal cord follows a circumferential trajectory that is believed to be steered by contact guidance cues, followed by attraction to and interaction with the floor plate (Colamarino and Tessier-Levigne, 1995). The site of axonogenesis for interneurons located dorsal to the motor column is from the leading (pial) process of the commissural interneuron, because contact with the circumferential pathway is made near the pial surface (see Fig. 6). But ventrally, where the $\mathrm{HN}$ neurons are generated, the circumferential pathway lies not at the pial surface, but rather medial to the lateral motor column. Because HN neurons eventually migrate past this point, their axons could derive either from the leading (pial) process or the trailing (ventricular) process, depending on the timing of axonogenesis and migration. This illustrates a potential diversity in the way commissural interneurons interact with their pathways.

\section{Termination pattern}

To our knowledge, this is the first description of the development of termination pattern by spinal interneurons in an amniote. Several features warrant mention. (1) Collateral sprouting does not begin until the full segmental range of the longitudinal axons is established. Such delayed sprouting has been observed in other axon systems (O'Leary et al., 1990), including large diameter primary sensory afferents (Davis et al., 1989; Eide and Glover, 1995) and descending axons (Glover and Eide, 1992) in the spinal cord of the chicken embryo. Collaterals sprout from these different spinal axon populations at approximately the same time, at $\mathrm{d} 7-\mathrm{d} 8$, suggesting a general signal within the spinal cord that induces collateral sprouting in all axons concomitantly. On the other hand, the HN axons seem to lag slightly the earliest developing commissural axons with respect to collateral sprouting, suggesting that a certain level of axon maturation is required before collateral sprouting. (2) Collateral sprouting occurs simultaneously along the length of the $\mathrm{HN}$ axon population. This might represent a developmental strategy that ensures that all $\mathrm{HN}$ collaterals interact with the same environmental cues within the gray matter during sprouting and terminal arborization. Because the spinal cord changes dramatically both in form and cellular composition after d8 (Eide and Glover, 1995), temporal discordance in the sprouting of collaterals along the length of the axons could lead to strikingly different patterns of connectivity along this length. (3) The position of the longitudinal axon shifts laterally within the ventrolateral white matter, such that proximal and distal collaterals issue from different positions along the perimeter. Despite this, the majority of collaterals along the entire length of the $\mathrm{HN}$ projection are directed roughly toward the central canal (see Fig. 10), bringing them into the medial region of the ventral horn. This behavior suggests a chemotropic attraction of HN collaterals by diffusible factors originating from the ventromedial gray matter. On the other hand, collateral angles are also roughly correlated with the angular postures of radial glia within the ventral spinal cord, suggesting a potential contact guidance function for these.

\section{REFERENCES}

Berkenblit MB, Feldman AG, Fukson OI (1989) Wiping reflex in the frog: movement patterns, receptive fields, and blends. In: Visuomotor coordination: amphibians, comparisons, models and robots (Ewert J-P, Arbib MA, eds), pp 615-630. New York: Plenum.
Bizzi E, Mussa-Ivaldi FA, Giszter S (1991) Computations underlying the execution of movement: a biological perspective. Science 253:287-291. Colamarino SA, Tessier-Lavigne M (1995) The role of the floor plate in axon guidance. Annu Rev Neurosci 18:497-529.

Dale N, Roberts A, Ottersen OP, Storm-Mathisen J (1987) The morphology and distribution of "Kolmer-Agduhr cells," a class of cerebrospinal-fluid-contacting neurons revealed in the frog embryo spinal cord by GABA immunocytochemistry. Proc R Soc Lond [Biol] 232:193-203.

Davis B, Frank E, Johnson F, Scott S (1989) Development of central projections of lumbosacral sensory neurons in the chick. J Comp Neurol 279:556-566.

Eide AL (1996) The axonal projections of the Hofmann nuclei in the spinal cord of the late stage chicken embryo. Anat Embryol (Berl) 193:543-557.

Eide AL, Glover J (1995) Development of the longitudinal projection pattern of lumbar primary sensory afferents in the chicken embryo. J Comp Neurol 353:247-259.

Eide AL, Glover J (1996) The developmental dynamics of functionally specific primary sensory afferent projections in the chicken embryo. Anat Embryol (Berl), in press.

Fukson OI, Berkenblit MB, Feldman AG (1980) The spinal frog takes into account the scheme of its body during the wiping reflex. Science 209:1261-1263.

Glover JC, Eide AL (1992) Temporal progression of descending axons in the chicken embryo spinal cord. Soc Neurosci Abstr 18:218.

Godement P, Vanselow J, Thanos S, Bonhoeffer F (1987) A study in developing visual systems with a new method of staining neurons and their processes in fixed tissue. Development 101:697-713.

Grillner S (1981) Control of locomotion in bipeds, tetrapods, and fish. In: Handbook of physiology, Sect 1, The nervous system, Vol 2, Motor control (Brooks VB, ed), pp 1179-1236. Bethesda: American Physiological Society.

Hamburger V, Hamilton H (1951) A series of normal stages in the development of the chick embryo. J Morphol 88:49-92.

Harrison PJ, Jankowska E, Zytnicki D (1986) Lamina VIII interneurones interposed in crossed reflex pathways in the cat. J Physiol (Lond) 371:147-166

Hollyday M, Hamburger V (1977) An autoradiographic study of the formation of the lateral motor column in the chick embryo. Brain Res 132:197-208.

Honig MG, Hume R (1986) Fluorescent carbocyanine dyes allow living neurons of identified origin to be studied in long term cultures. J Cell Biol 103:171-187.

Jacobson M (1991) Developmental neurobiology. New York: Plenum.

Jankowska E, Noga BR (1990) Contralaterally projecting lamina VIII interneurons in middle lumbar segments in the cat. Brain Res 535:327-330

Kopriwa B, LeBlond CP (1962) Improvements in the coating technique of radioautography. J Histochem Cytochem 10:269-284.

Kuwada JY, Bernhardt RR, Chitnis AB (1990a) Pathfinding by identified growth cones in the spinal cord of zebrafish embryos. J Neurosci 10:1299-1308.

Kuwada JY, Bernhardt RR, Nguyen N (1990b) Development of spinal neurons and tracts in the zebrafish embryo. J Comp Neurol 302:617-628.

Langman J, Haden CC (1970) Formation and migration of neuroblasts in the spinal cord of the chick embryo. J Comp Neurol 138:419-432.

Leber SM, Sanes JR (1995) Migratory paths of neurons and glia in the embryonic chick spinal cord. J Neurosci 15:1236-1248.

Leber SM, Breedlove SM, Sanes JR (1990) Lineage, arrangement, and death of clonally related motoneurons in chick spinal cord. J Neurosci 10:2451-2462.

Martin A, Langman J (1965) The development of the spinal cord examined by autoradiography. J Embryol Exp Morphol 14:25-35.

McConnell JA, Sechrist JW (1980) Identification of early neurons in the brainstem and spinal cord. I. An autoradiographic study in the chick. J Comp Neurol 192:769-783.

McConnell SK (1992) The determination of neuronal identity in the mammalian cerebral cortex. In: Determinants of neuronal identity (Shankland M, Macagno ER, eds), pp 391-432. San Diego: Academic. Mussa-Ivaldi FA, Giszter SF, Bizzi E (1994) Linear combinations of primitives in vertebrate motor control. Proc Natl Acad Sci USA 91:7534-7538. 
O'Leary DD, Bicknese AR, De Carlos JA, Heffner CD, Koester SE, Kutka LJ, Terashima T (1990) Target selection by cortical axons: alternative mechanisms to establish axonal connections in the developing brain. Cold Spring Harb Symp Quant Biol 55:453-468.

Oppenheim RW, Shneiderman A, Shimizu I, Yaginuma H (1988) Onset and development of intersegmental projections in the chick embryo spinal cord. J Comp Neurol 275:159-180.

Pflüger E (1853) Die sensorischen Functionen des Rückenmarks der Wirbeltiere. Berlin: August Hirschwald.

Roberts A, Dale N, Ottersen OP, Storm-Mathisen J (1987) The early development of neurons with GABA immunoreactivity in the CNS of Xenopus laevis embryos. J Comp Neurol 261:435-449.

Roberts A, Dale N, Ottersen OP, Storm-Mathisen J (1988) Development and characterization of commissural interneurones in the spinal cord of Xenopus laevis embryos revealed by antibodies to glycine. Development 103:447-461.
Stein PSG (1989) Spinal cord circuits for motor pattern selection in the turtle. Ann NY Acad Sci 563:1-10.

Tsuchida T, Ensini M, Morton SB, Baldassare M, Edlund T, Jessell TM, Pfaff SL (1994) Topographic organization of embryonic motor neurons defined by expression of LIM homeobox genes. Cell 79:957-970.

Yaginuma H, Shiga T, Homma S, Ishihara R, Oppenheim RW (1990) Identification of early developing axon projections from spinal interneurons in the chick embryo with a neuron specific beta-tubulin antibody: evidence for a new "pioneer" pathway in the spinal cord. Development 108:705-716.

Yaginuma A, Homma S, Künzi R, Oppenheim RW (1991) Pathfinding by growth cones of commissural interneurons in the chick embryo spinal cord: a light and electron microscopic study. J Comp Neurol 304:78-102.

Yaginuma H, Shiga T, Oppenheim RW (1994) Early developmental patterns and mechanisms of axonal guidance of spinal interneurons in the chick embryo spinal cord. Prog Neurobiol 44:249-278. 